\title{
Shewanella algae Bacteremia in an End-stage Renal Disease Patient: A Case Report and Review of the Literature
}

\author{
Tomoaki Takata ${ }^{1}$, Hiroki Chikumi ${ }^{2}$, Shota Morishita ${ }^{3}$, Shintaro Hamada ${ }^{1}$, Shotaro Hoi ${ }^{1}$, \\ Takuji Iyama ${ }^{1}$, Takeaki Fukui ${ }^{1}$, Tomomitsu Matono ${ }^{1}$, Satoko Fukuda ${ }^{1}$, \\ Chishio Munemura ${ }^{1}$ and Hajime Isomoto ${ }^{1}$
}

\begin{abstract}
A 71-year-old man was admitted because of nausea and abdominal pain. He was receiving an erythropoiesis-stimulating agent for anemia and dysregulated iron metabolism due to stage G5 chronic kidney disease. He had a history of raw fish intake and was diagnosed with infectious enterocolitis, which worsened and led to septic shock. Shewanella putrefaciens grew in the blood culture, but Shewanella algae was identified in a 16S rRNA gene sequence analysis. We herein report a case of $S$. algae bacteremia believed to have been transmitted orally. We also reviewed previous case reports on Shewanella infection in end-stage renal disease patients.
\end{abstract}

Key words: anemia, chronic kidney disease, fish, iron, oral infection, sepsis

(Intern Med 56: 729-732, 2017)

(DOI: 10.2169/internalmedicine.56.7616)

\section{Introduction}

Shewanella algae is an unusual pathogenic bacterium in humans. Most cases were reported in patients with chronic liver disease and cancer, and cases of $S$. algae infection in end-stage renal disease (ESRD) patients are few. The problems related to clinical practice are that little is known about the etiology of $S$. algae infection in ESRD patients and that this bacterium is often confused with Shewanella putrefaciens, although these two species may have different pathogenicities in humans. We herein report a case of $S$. algae bacteremia in a patient with ESRD and review previous case reports on Shewanella infection in ESRD patients.

\section{Case Report}

A 71-year-old man was admitted to our hospital in midJuly because of a 5-day history of nausea and abdominal pain. He had been diagnosed with chronic kidney disease (CKD) due to chronic glomerulonephritis and had had an ar- teriovenous fistula in his left arm in preparation for renal replacement therapy since two month prior to the onset. He had been given an erythropoiesis-stimulating agent (ESA; darbepoetin alpha $180 \mu \mathrm{g} / \mathrm{month}$ ) for renal anemia; he was not on any iron supplements. The laboratory data 1 month before the onset of symptoms showed hemoglobin of $6.9 \mathrm{~g} /$ $\mathrm{dL}, \mathrm{Fe}$ of $141 \mu \mathrm{g} / \mathrm{dL}$, transferrin saturation (TSAT) of $76.6 \%$, and ferritin of $704 \mathrm{ng} / \mathrm{mL}$, findings that were indicative of dysregulated iron metabolism.

He had eaten sliced raw fish or "sashimi" of mackerel and squid three days before the manifestations of nausea and abdominal pain, for which he visited the outpatient unit, where he was diagnosed with infectious enterocolitis and was given oral fosfomycin. However, his symptoms worsened, and he was admitted to our hospital five days after the onset of symptoms.

A physical examination showed that his blood pressure was $160 / 70 \mathrm{mmHg}$, heart rate 83 beats/min, and body temperature $39.5^{\circ} \mathrm{C}$. He had abdominal tenderness without rebound tenderness. No remarkable findings were observed in the heart sounds or respiratory sounds. Leg edema was not

${ }^{1}$ Division of Medicine and Clinical Science, Tottori University Faculty of Medicine, Japan, ${ }^{2}$ Center for Infectious Diseases, Tottori University Hospital, Japan and ${ }^{3}$ Division of Clinical Laboratory, Tottori University Hospital, Japan

Received for publication April 21, 2016; Accepted for publication June 30, 2016

Correspondence to Dr. Tomoaki Takata, t-takata@med.tottori-u.ac.jp 

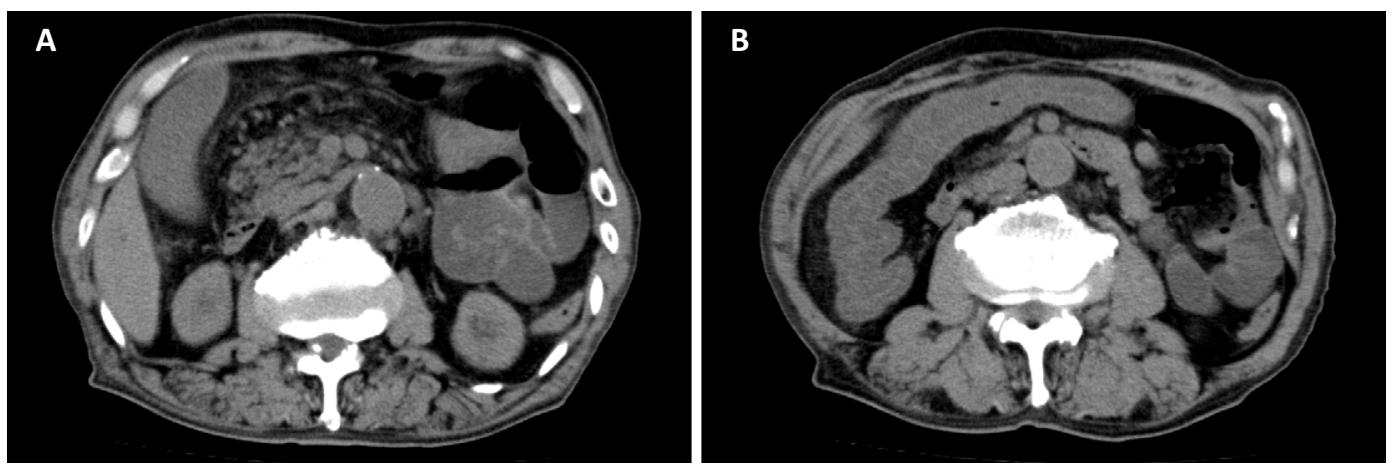

Figure. A, B: Abdominal computed tomography on admission revealed intestinal swelling and fluid collection, compatible with infectious enterocolitis.

Table 1. Antibiotic Susceptibility Test.

\begin{tabular}{lr}
\hline Antibiotics & \multicolumn{1}{c}{$\begin{array}{l}\text { MIC } \\
(\mu \mathrm{g} / \mathrm{mL})\end{array}$} \\
\hline Piperacillin & $<8$ \\
Ceftazidime & $<4$ \\
Cefepime & $<2$ \\
Cefozopran & $<4$ \\
Sulbactam / Cefoperazone & $<16$ \\
Imipenem & $<1$ \\
Meropenem & $<1$ \\
Aztreonam & $<4$ \\
Amikacin & $<8$ \\
Levofloxacin & $<0.5$ \\
Tazobactam / Piperacillin & $<8$ \\
\hline MIC: minimum inhibitory concentration &
\end{tabular}

seen. Laboratory tests on admission showed a white blood cell count of $3,700 / \mu \mathrm{L}$ with $83 \%$ segmented neutrophils, hemoglobin of $7.6 \mathrm{~g} / \mathrm{dL}$, mean corpuscular volume (MCV) of $93.4 \mathrm{fL}$, mean corpuscular hemoglobin $(\mathrm{MCH})$ of $30.2 \mathrm{pg}$, mean corpuscular hemoglobin concentration (MCHC) of $32.5 \mathrm{~g} / \mathrm{dL}$, and platelet count of $156,000 / \mu \mathrm{L}$. Serum chemistries showed serum sodium $134 \mathrm{mEq} / \mathrm{L}$, potassium $5.0 \mathrm{mEq} /$ $\mathrm{L}$, chloride $91 \mathrm{mEq} / \mathrm{L}$, calcium $5.0 \mathrm{mg} / \mathrm{dL}$, phosphorus 11.7 $\mathrm{mg} / \mathrm{dL}$, magnesium $1.6 \mathrm{mg} / \mathrm{dL}$, uric acid $11.8 \mathrm{mg} / \mathrm{dL}$, blood urea nitrogen $166.9 \mathrm{mg} / \mathrm{dL}$, creatinine $23.0 \mathrm{mg} / \mathrm{dL}$, total protein $6.8 \mathrm{~g} / \mathrm{dL}$, albumin $2.8 \mathrm{~g} / \mathrm{dL}$, aspartate aminotransferase $27 \mathrm{U} / \mathrm{L}$, alanine transaminase $19 \mathrm{U} / \mathrm{L}$, lactate dehydrogenase $882 \mathrm{U} / \mathrm{L}$, alkaline phosphatase $210 \mathrm{U} / \mathrm{L}, \gamma$-glutamyl transpeptidase $19 \mathrm{U} / \mathrm{L}$, creatine kinase 1,809 U/L, and Creactive protein $11.7 \mathrm{mg} / \mathrm{dL}$. Abdominal computed tomography (CT) revealed intestinal swelling and fluid collection, compatible with infectious enterocolitis (Figure).

Two sets of blood cultures were collected before cefmetazole ( $1 \mathrm{~g}$ /day) was started. On the second hospital day, he went into cardiac arrest; cardiopulmonary resuscitation resulted in the return of spontaneous circulation. Catecholamine, mechanical ventilation, and continuous hemodiafiltration were started. Antimicrobial therapy was changed to meropenem ( $2 \mathrm{~g} /$ day). On the third hospital day, gramnegative bacteria appeared in both sets of the blood culture obtained on admission and were identified as $S$. putrefaciens 4 days later. Ceftazidime ( $2 \mathrm{~g} /$ day) was given based on the susceptibility test (Table 1).
His condition improved; therefore, continuous hemodiafiltration was switched to hemodialysis 3 times per week. A stool culture collected on the eighth hospital day was negative. On the 13th hospital day, the antimicrobial agent was changed to levofloxacin and continued for 1 week. He was discharged on the 26th hospital day without any complications and continued maintenance hemodialysis. The bacterium recovered from the blood culture was further analyzed because the patient's condition had deteriorated. A $16 \mathrm{~S}$ rRNA gene sequence analysis revealed that the bacterium was S. algae.

\section{Discussion}

S. algae is a rare causative pathogen of bacteremia, skin and soft tissue infection, or hepatobiliary infection. We reported a case of S. algae bacteremia in an ESRD patient and demonstrated the probable link between raw seafood consumption and Shewanella infection. This patient had iron overload that was related to a dysregulated iron metabolism caused by ESRD. Raw seafood consumption by an ESRD patient may be a risk factor for Shewanella infection.

Shewanella species are Gram-negative bacteria that are mainly isolated from the marine environment. This species was once named Pseudomonas putrefaciens; it was originally classified in the family Vibrioneceae until the 1990s, when it was reclassified as genus Shewanella (1). Most case reports of Shewanella infection have described an association with exposure to seawater; such contact can cause ear infection, skin or soft tissue infection, and bacteremia (1-3). Two species, S. putrefaciens and S. algae, have been reported to be pathogenic in humans (1). It is often difficult to distinguish between these two species, because automated identification systems only include the database of $S$. putrefaciens, but not S. algae (2). Therefore, some authors have suggested that the previously reported $S$. putrefaciens infections may have actually been caused by $S$. algae, which is thought to be more virulent (3). The accurate distinction between these two species requires a 16S rRNA gene sequence analysis or phenotypic tests; $S$. algae can only grow at $42^{\circ} \mathrm{C}$ and in $6 \% \mathrm{NaCl}(1)$. In the present case, an automated identification system (MicroScan WalkAway 96 Plus, 
Table 2. Characteristics of ESRD Patients with Shewanella Infection.

\begin{tabular}{|c|c|c|c|c|c|c|c|c|c|}
\hline Case & Reference & Country & Age & Sex & $\begin{array}{l}\text { Shewanella } \\
\text { species }\end{array}$ & Focus & $\begin{array}{l}\text { Route of } \\
\text { infection }\end{array}$ & Antibiotic therapy & Outcome \\
\hline 1 & 6 & Australia & 62 & $\mathrm{M}$ & S. putrefaciens & $\begin{array}{l}\text { Oligoarthritis, } \\
\text { bacteremia }\end{array}$ & $\begin{array}{l}\text { Respiratory } \\
\text { tract }\end{array}$ & $\begin{array}{l}\text { FLUX, GM, } \\
\text { PIPC, CPFX }\end{array}$ & Survival \\
\hline 2 & 7 & Japan & 64 & $\mathrm{~F}$ & S. algae & Bacteremia & Unknown & $\begin{array}{l}\text { CEZ, GM, } \\
\text { LVFX, MINO, } \\
\text { CFPM }\end{array}$ & Survival \\
\hline 3 & 8 & Australia & 69 & M & S. putrefaciens & $\begin{array}{l}\text { Splenic abscess, } \\
\text { bacteremia }\end{array}$ & Skin ulcer & Unknown & Survival \\
\hline 4 & 9 & USA & 58 & M & S. algae & $\begin{array}{l}\text { Myonecrosis, } \\
\text { bacteremia }\end{array}$ & Skin ulcer & CFPM & Survival \\
\hline 5 & 4 & Korea & 67 & M & S. putrefaciens & $\begin{array}{l}\text { Necrotizing fasciitis, } \\
\text { bacteremia }\end{array}$ & Skin ulcer & $\begin{array}{l}\text { CAZ, MEPM, } \\
\text { VCM, DOXY, } \\
\text { GM }\end{array}$ & Death \\
\hline 6 & 10 & USA & 78 & M & S. putrefaciens & Bacteremia & Catheter & GM, MEPM & Survival \\
\hline 7 & 11 & Taiwan & 82 & $\mathrm{~F}$ & S. putrefaciens & Bacteremia & Catheter & DRPM, AMK & Survival \\
\hline 8 & $\begin{array}{l}\text { Present } \\
\text { case }\end{array}$ & Japan & 71 & M & S. algae & $\begin{array}{l}\text { Infectious } \\
\text { enterocolitis, } \\
\text { bacteremia }\end{array}$ & Oral & $\begin{array}{l}\text { MEPM, CAZ, } \\
\text { LVFX }\end{array}$ & Survival \\
\hline
\end{tabular}

ESRD: end-stage renal disease, FLUX: flucloxacillin, GM: gentamicin, PIPC: piperacillin, CPFX: ciprofloxacin, CEZ: cefazolin, LVFX: levofloxacin, MINO: minocycline, CFPM: cefepime, CAZ: ceftazidime, MEPM: meropenem, VCM: vancomycin, DOXY: doxycycline, DRPM: doripenem, AMK: amikacin

Siemens Healthcare Diagnostics, Tokyo, Japan) initially determined the bacterium to be S. putrefaciens; however, a $16 \mathrm{~S}$ rRNA gene sequence analysis confirmed the bacterium to be S. algae.

Shewanella infection can be fulminant and fatal and is often misdiagnosed as Vibrio vulnificus infection, because of the similarities in their clinical manifestations $(2,4)$. Patients with underlying diseases, such as hepatobiliary disease or malignancy, were reported to be predisposed to Shewanella infection, as well as to V. vulnificus infection (3); the mortality rate of Shewanella bacteremia was increased in these patients (5). Shewanella species belong to the microflora of the marine environment, and exposure to seawater was reported to be one of the risk factors for Shewanella infection, especially in temperature regions (3). Therefore, more attention should be paid to the pathogenicity of this bacterium, especially in patients with underlying diseases who are exposed to these environments.

Shewanella infection in ESRD patients has rarely been reported. To our knowledge, there have been seven previously published case reports on Shewanella infection in ESRD patients (4, 6-11) (Table 2). All of these cases were from geographic areas with long shorelines. Two cases were reported to be caused by S. algae and four cases by S. putrefaciens; however, only two cases were further analyzed by a biochemical procedure. Five cases showed bacteremia, and one case died of necrotizing myositis. The most common route of infection was skin ulcer (3 cases), followed by catheterrelated infection ( 2 cases); no case was related to oral intake of seafood. In the present case, the onset of symptoms was related to seafood consumption, and abdominal CT scan showed signs of infectious enterocolitis. Therefore, we concluded that the Shewanella infection in this patient was probably caused by dietary intake of raw fish or "sashimi". This was the first case of $S$. algae infection that might have been transmitted orally in an ESRD patient.
Although the reason why the ESRD patient was predisposed to Shewanella infection is still unclear, dysregulated iron metabolism may be a risk factor for this patient. Iron is an essential element for bacterial growth. In the mammalian host, iron is not freely available, since it binds to transferrin in the blood (12). Pseudomonas and Vibrio species have the ability to produce siderophore, which plays an important role in supplying iron to bacteria $(12,13)$. Siderophore has a high affinity to iron and is able to displace iron from transferrin. S. algae was reported to produce siderophore and was capable of absorbing iron into its body (14). Patients with hepatobiliary diseases who are susceptible to $S$. algae often had the complication of iron overload. The association between Shewanella infection and hepatobiliary diseases may be due to iron overload (5). In the present case, the patient did not have hepatic dysfunction but did have ESRD with a dysregulated iron metabolism; his anemia was ESAresistant, and there seemed to be excessive iron levels, although he was not taking any iron supplement. It was suspected that uremia of the patient contributed to the ESAresistant anemia, because the patient was just starting renal replacement therapy, and the serum creatinine level on admission was extremely high. Recent studies have demonstrated that hepcidin, which reduces iron release from reticuloendothelial and hepatocyte stores, plays an important role in the disordered iron metabolism of uremia including ESA resistance $(15,16)$. The serum hepcidin level is related to the residual renal function and elevates in CKD and in ESRD patients $(15,17)$. Serum hepcidin can be removed by renal replacement therapy (18), and insufficient hemodialysis is known to cause ESA-resistant anemia (19). Therefore, we speculated that the ESRD, especially the accompanying iron overload, might have been a risk factor for Shewanella infection in this patient. To our knowledge, no previous report has described the status of iron metabolism in the ESRD patients with Shewanella infection. Therefore, further investi- 
gation is required to validate this issue.

The limitation of this report was that the data for serum ferritin and TSAT on admission were not available. However, we measured both of these markers at one month before the onset, when the patient was in a stable condition without acute inflammation or infection. Iron status should be evaluated based on ferritin and TSAT in CKD and ESRD patients $(19,20)$. The ferritin level and TSAT of the patient in the present study were compatible with iron overload $(21,22)$. In addition, we were unable to recover $S$. algae from a stool culture on the eighth hospital day, when the patient had already received courses of an antimicrobial agent to which the bacterium was susceptible. We could not collect a stool sample at an earlier time, such as at admission, because of the patient's critically ill condition.

In conclusion, we reported a case of $S$. algae bacteremia that was probably caused by oral intake of raw fish in an ESRD patient. In addition, a dysregulated iron metabolism in ESRD may be a risk factor for Shewanella infection.

The authors state that they have no Conflict of Interest (COI).

\section{References}

1. Holt HM, Gahrn-Hansen B, Bruun B. Shewanella algae and Shewanella putrefaciens: clinical and microbiological characteristics. Clin Microbiol Infect 11: 347-352, 2005.

2. Otsuka T, Noda T, Noguchi A, Nakamura H, Ibaraki K, Yamaoka K. Shewanella infection in decompensated liver disease: a septic case. J Gastroenterol 42: 87-90, 2007.

3. Vignier N, Barreau M, Olive C, et al. Human infection with Shewanella putrefaciens and S. algae: report of 16 cases in Martinique and review of the literature. Am J Trop Med Hyg 89: 151156, 2013.

4. Yim SY, Kang YS, Cha DR, et al. Fatal PD peritonitis, necrotizing fasciitis, and bacteremia due to Shewanella putrefaciens. Perit Dial Int 30: 667-669, 2010.

5. Liu PY, Lin CF, Tung KC, et al. Clinical and microbiological features of Shewanella bacteremia in patients with hepatobiliary disease. Intern Med 52: 431-438, 2013.

6. Roger SD, Chen SC, Lawrence S, Sorrell TC. Pseudomonas putrefaciens bacteraemia in a peritoneal dialysis patient. Nephrol Dial Transplant 6: 73, 1991.

7. Iwata M, Tateda K, Matsumoto $T$, Furuya N, Mizuiri S, Yamaguchi K. Primary Shewanella alga septicemia in a patient on hemodialysis. J Clin Microbiol 37: 2104-2105, 1999.
8. Bhandari S, Pan TL, Horvath J, Tiller D. CAPD, swimming in Shewanella. Nephrol Dial Transplant 15: 1484-1485, 2000.

9. Jammula P, Gupta R, Agraharkar M. Vascular steal syndrome and Shewanella alga infection requiring amputation in a hemodialysis patient. Saudi J Kidney Dis Transpl 14: 511-515, 2003.

10. Shrishrimal K. Recurrent Ochrobactrum anthropi and Shewanella putrefaciens bloodstream infection complicating hemodialysis. Hemodial Int 16: 113-115, 2012.

11. Lee WS, Ou TY, Chen FL, Hsu CW, Jean SS. Shewanella putrefaciens bacteremia in a uremic patient receiving hemodialysis. $\mathrm{J}$ Microbiol Immunol Infect 49: 159-160, 2016.

12. Cornelis P, Dingemans J. Pseudomonas aeruginosa adapts its iron uptake strategies in function of the type of infections. Front Cell Infect Microbiol 3: 75, 2013.

13. Tan W, Verma V, Jeong $\mathrm{K}$, et al. Molecular characterization of vulnibactin biosynthesis in Vibrio vulnificus indicates the existence of an alternative siderophore. Front Microbiol 5: 1, 2014.

14. Gram L. Siderophore-mediated iron sequestering by Shewanella putrefaciens. Appl Environ Microbiol 60: 2132-2136, 1994.

15. van der Weerd NC, Grooteman MP, Bots ML, et al; CONTRAST Investigators. Hepcidin-25 in chronic hemodialysis patients is related to residual kidney function and not to treatment with erythropoiesis stimulating agents. PLos One 7: e39783, 2012.

16. Ashby DR, Gale DP, Busbridge M, et al. Plasma Hepcidin levels are elevated but responsive to erythropoietin therapy in renal disease. Kidney Int 75: 976-981, 2009.

17. Troutt JS, Butterfield AM, Konrad RJ. Hepcidin-25 concentrations are markedly increased in patients with chronic kidney disease and are inversely correlated with estimated glomerular filtration rates. J Clin Lab Anal 27: 504-510, 2013.

18. Weiss G, Theurl I, Eder S, et al. Serum Hepcidin concentration in chronic haemodialysis patients: associations and effects of dialysis, iron and erythropoietin therapy. Eur J Clin Invest 39: 883-890, 2009.

19. Guideline working group, Japanese Society for Dialysis Therapy Clinical Practice of Renal Anemia. Nihon Toseki Igakukai Zasshi 49: 89-158, 2016 (in Japanese).

20. Kidney Disease: Improving Global Outcomes (KDIGO) Anemia Work Group. KDIGO clinical practice guideline for anemia in chronic kidney disease. Kidney Int 2(Suppl): 279-335, 2012.

21. Rostoker G, Griuncelli M, Loridon C, et al. Reassessment of iron biomarkers for prediction of dialysis iron overload: an MRI study. PLoS One 16: e0132006, 2015.

22. Canavese C, Bergamo D, Ciccone G, et al. Validation of serum ferritin values by magnetic susceptometry in predicting iron overload in dialysis patients. Kidney Int 65: 1091-1098, 2004.

The Internal Medicine is an Open Access article distributed under the Creative Commons Attribution-NonCommercial-NoDerivatives 4.0 International License. To view the details of this license, please visit (https://creativecommons.org/licenses/ by-nc-nd/4.0/).

(C) 2017 The Japanese Society of Internal Medicine http://www.naika.or.jp/imonline/index.html 